\title{
Religious Coping Strategies During COVID-19 Outbreak and Anxiety Face at the Total Lockdown Resolution Among Tunisian People
}

\author{
Ajmi Sirine, Hentati Salma, Sallemi Rim, Masmoudi Rim, Feki Ines, Masmoudi Jaweher \\ Psychiatric A Department, Hedi Chaker Hospital University, Sfax, Tunisia \\ Email address: \\ Syrine-aj@hotmail.com (A. Sirine) \\ To cite this article: \\ Ajmi Sirine, Hentati Salma, Sallemi Rim, Masmoudi Rim, Feki Ines, Masmoudi Jaweher. Religious Coping Strategies During COVID-19 \\ Outbreak and Anxiety Face at the Total Lockdown Resolution Among Tunisian People. Psychology and Behavioral Sciences. \\ Vol. 10, No. 4, 2021, pp. 134-138. doi: 10.11648/j.pbs.20211004.12
}

Received: June 19, 2021; Accepted: July 13, 2021; Published: August 2, 2021

\begin{abstract}
Background: coronavirus, a highly contagious virus, spreads quickly and can be fatal in severe cases. With no specific medicines, it constitute not only threat to the life and health of people but has also a large impact on their mental health and coping strategies. We assessed the religious coping strategies in COVID-19 pandemic and determinate the level of anxiety face to the end of the lockdown in a sample of $n=80$ Tunisian. Methods: An online questionnaire survey was conducted from 24 April to 23 May 2020 to evaluate anxiety face to the end of lockdown and religious coping responses face to the outbreak of COVID-19 pandemic. We used the brief religious coping scale (R-COPE) and Hospital anxiety and depression scale-anxiety (HADS-A). Results: Two-thirds of the participants exhibited anxiety symptoms at the end of the total lockdown. The negative religious coping was much less prevalent than positive religious coping. Significant relationships were found only for demographic variables: Higher educated reported more positive religious coping. No correlation was found between religious commitment and religious coping. Participants with positive religious coping style have higher level of anxiety during lockdown resolution. In conclusion, the COVID-19 outbreak in Tunisia had an impact on the mental health status of the general public even after the lockdown resolution.
\end{abstract}

Keywords: Coping, Anxiety, Tunisian People, Religion, Corona Virus, Lockdown

\section{Introduction}

The outbreak of corona virus disease 2019 (COVID-19), known as Severe Acute Respiratory Syndrome Corona virus 2 (SARS-CoV-2), caused by a new corona virus (Wu et al., 2020) was discovered for the first time in December 2019 in Wuhan (China) and spread rapidly in almost all regions of the globe [1]. As Respiratory disease, this virulent virus is transmitted by breathing of infected droplets or contact with infected droplets. In March, the World Health Organization (WHO) declared the COVID-19 pandemic a global public health emergency [2].

Tunisia was one of the countries involved in the epidemic since March 2, 2020. In response to the growing pandemic of COVID-19 in the country, on 20 March, a total confinement on the 30 entire national territory was announced to help contain the spread of COVID-19 [3].
So, a national lockdown is imposed and all individuals were quarantined and forced to maintain strict social distancing from other people.

It is well established that such stressful events can have a significant impact on individuals' psychological and physical well-being [4]. Worldwide, this crisis of COVID-19 pandemic and lockdown are generating stress throughout the population. During this difficult time of COVID-19 pandemic, when a lot of stress, fear and confusion prevail, religious teachings can be very helpful in mitigating these conditions.

To our knowledge, no national study has investigated religious coping strategy during the current situation. To provide preliminary evidence, we conducted this study of the general Tunisian adult population. It aims to evaluate anxiety face at the end of lockdown and religious coping responses face to the outbreak of COVID-19 pandemic. 


\section{Materials and Methods}

The survey was conducted using the online anonymous questionnaires and distributed through social networks from 24 April to 23 May 2020 (which was considered the end of the lockdown in Tunisia).

It included socio-demographic questions, participants' experience of SARS-CoV-2related stressful events (A member of your family was suspected of having Corona virus /someone you know had Corona virus symptoms /You were quarantined) and tow questionnaires: Hospital Anxiety and Depression scale (HADS) and brief religious coping scale (R-cope). It also asked participants to rate the frequency of religious practice during the COVID-19 pandemic.

\subsection{Hospital Anxiety and Depression Scale-anxiety (HADS-A)}

The HADS questionnaire has seven items each for depression and anxiety subscales. Scoring for each item ranges from zero to three, with three denoting highest anxiety level. The total score vary from 0 to 21 . The interpretation of scores recommended: $0-7$ for normal or no anxiety, $8-10$ for mild anxiety, 11-14 for moderate anxiety, and 12-21 for severe anxiety [5].

\subsection{Brief Religious Coping Scale (R-COPE)}

The Brief R-COPE is composed of 14 items that measure religious coping with major life stressors. As the most commonly used measure of religious coping in the literature, it has helped contribute to the enrich of knowledge about the role religion serves in the process of dealing with crisis, trauma, and transition. The items themselves were generated through interviews with people experiencing major life stressors. It is a 14 - item measure with two seven - item subscales for positive and negative religious coping. It is scaled from 1 to 4 ( 1 = "not at all", 4= "a lot"), with subscale totals ranging from 7 to 28 . Positive and negative religious coping were considered present if the subscale score was respectively superior to 20 and 16 .

Positive religious coping (PRC) methods reflect a secure relationship with a transcendent force, a sense of spiritual connectedness with others, and a benevolent world view. Negative religious coping (NRC) methods reflect underlying spiritual tensions and struggles within oneself, with others, and with the divine [6].

\section{Results}

\subsection{Socio-demographic Factors}

Our study included 80 participants: 71.3\%participants were female and $42.5 \%$ were married. The age of the participants ranged from 20 to 57 years, with an average age of 29.30 years $(\mathrm{SD}=8.72)$.

All participants were Muslims, and $72.5 \%$ of them had religious practices. With the start of the lockdown, two thirds of the participants had multiplied their practices
A description of sociodemographic features, participants' experience of COVID-19 related stressful events and religious commitment's activity are given in Table 1.

Table 1. Descriptive statistics of socio-demographic variables.

\begin{tabular}{ll}
\hline Criteria & Total \\
\hline Male (\%) & 28.8 \\
Mean Age (Years Old) & 29.33 \\
Marital Status (\%): & \\
Married & 42.5 \\
Divorced & 2.5 \\
Single & 53.8 \\
Widow & 1.3 \\
School (\%): & \\
primary school & 6.3 \\
secondary school & 3.7 \\
University & 90 \\
Alcohol (\%) & 6.3 \\
Smoking (\%) & 7.5 \\
Co morbidities (Others than Psychiatric Disorders) (\%) & 11.3 \\
Psychiatric co morbidities (\%) & 5 \\
Profession & \\
Unemployed/housewife (\%) & \\
Experience with CORONA (\%) & 5 \\
A member of your family was suspected of having Corona virus & 7.5 \\
someone you know had Corona virus 's symptoms & 15 \\
You were quarantined & 22.5 \\
Religious activity (\%): & \\
Yes & 72.5 \\
Increased in this current situation & 66.3 \\
\hline &
\end{tabular}

\subsection{Experience of SARS-cov-2-related Stressful Events}

In our study, $7.5 \%$ of participants reported having a member of their family with confirmed or suspected COVID$19,15 \%$ reported that someone close to them had a confirmed or suspected infection and $22.5 \%$ reported having a confirmed or suspected infection themselves.

\subsection{Anxiety}

The mean HADS-A score was $8.03 \quad(\mathrm{SD}=2.938)$ (maximum $=16$ minimum $=1$ ).

Two-thirds of the participants exhibited anxiety symptoms $(66.3 \%)$ with only $1.3 \%$ reported severe anxiety symptoms (table 2)

Table 2. Descriptive statistics of anxiety.

\begin{tabular}{ll}
\hline Anxiety (\%) & 66.3 \\
No anxiety (\%) & 33,8 \\
Mild anxiety (\%) & 31,3 \\
Moderate anxiety (\%) & 33,8 \\
Severe anxiety (\%) & 1,3 \\
\hline
\end{tabular}

\subsection{Religious Coping and Its Correlate Factors}

The mean scores for positive and negative religious coping were $18.31 \pm 5.38$ and $9.51 \pm 3.21$, respectively.

The percentage of participants who used PRC was $37.50 \%$. NRC was much less prevalent: only 5\% used NRC. (Table 3 ) 
Table 3. Descriptive statistics of religious coping.

\begin{tabular}{ll}
\hline Positive RCOPE score & $18.35(\mathrm{SD}=5.38)$ \\
Negative RCOPE score & $9.51(\mathrm{SD}=3.21)$ \\
Positive coping Present $(\%)$ & 37.5 \\
Negative Coping Present $(\%)$ & 5 \\
\hline
\end{tabular}

Table 4 reports correlation for religious coping.

Table 4. Associations of demographics, experiences with corona and anxiety with religious coping.

\begin{tabular}{lll}
\hline Item & $\begin{array}{l}\text { Positive } \\
\text { RCOPE }\end{array}$ & $\begin{array}{l}\text { Negative } \\
\text { RCOPE }\end{array}$ \\
\hline Gender & 0.180 & 0.192 \\
Age & 0.829 & 0.109 \\
Marital status: married & 0.385 & 0.382 \\
Education level: high & 0.002 & 0.494 \\
Religious practice & 0.897 & 0.504 \\
Increasing Religious practice & 0.013 & 0.035 \\
A member of your family was suspected of & 0.016 & 0.173 \\
having Corona virus & & \\
someone you know had Corona virus 's & 0.112 & 0.060 \\
symptoms & 0.489 & 0.100 \\
You were quarantined & 0.044 & 0.143 \\
Anxiety & & \\
\hline
\end{tabular}

There were no significant differences in religious coping activities as a function of gender $(p=0.180, p=0.192)$.

We found that higher-educated participant reported more $\operatorname{PRC}(\mathrm{p}=0.002)$.

Having a family member with a suspected or confirmed infection was correlated with PRC $(p=0.016)$. Concern with becoming infected or having a friend with a suspected or confirmed infection did not correlate with any coping strategy $(p=0.112 ; p=0.489)$.

No correlation was found between religious commitment and religious coping $(\mathrm{p}=0.897 ; \mathrm{p}=0.504)$ however, increasing religious activity during this pandemic was correlated with $\operatorname{PRC}(\mathrm{p}=0.013)$.

Anxiety was positively tied to PRC: those with PRC style have higher levels of anxiety during lockdown resolution $(\mathrm{p}=0.044)$.

\section{Discussion}

The aims of the present study were to evaluate anxiety face at the end of the lockdown and to determinate coping strategies in COVID-19 pandemic and its correlate factors among the adult general population.

\subsection{Anxiety on the Lockdown Resolution}

You would think that by the end of the total lockdown due to the corona virus pandemic on Mai 4, the feeling of regaining freedom and movement would be good for our morale. Unfortunately, it's not that simple. In fact, $63.8 \%$ of the survey respondents of our study stated to be anxious about the consequences of the end of this lockdown on their life and $1.3 \%$ of cases presented sever anxiety.

It seems that for many of our participants, the end of total lockdown would be distressing as the confinement was. Although the health risk, far from disappearing, would tend to diminish, Tunisians are not regaining immediate confidence in the future and the climate remains anxious.

The main reason may be that, first, as a Jeong and al reported, people who were in quarantine continued to have anxiety symptoms even four to six months after announcing the end of the total isolation [7]. Brooks and al showed that although quarantine is a necessary preventive measure, it is often associated with a negative psychological effect that can still be detected months or years later [8].

In fact, long after Hong Kong was formally declared by the WHO as being free from further SARS transmission (SARS epidemic caused by a corona virus in Hong Kong in March 2003) many people continued to avoid going out of their homes. They also continued to engage in infection prevention acts such as sterilized cleaning of their home environments [9].

Second, financial loss can be a problem during quarantine, with people unable to work and having to interrupt their professional activities. Such effects appear to be long lasting [10]. In the reviewed study [8], the financial loss as a result of quarantine created serious socioeconomic distress was found to be a risk factor for psychological disorders symptoms, especially anxiety, several months after quarantine.

Third, another study suggest that participants' anxiety after lockdown resolution may be associated with especially ongoing concern about second wave, the fear of another outbreak, uncertainty regarding the treatment process and outcomes, the well-being of loved ones and their economic situation and disruption in work life [11].

\subsection{Religious Coping and Correlate Factors}

It is notable that participants reported that COVID-19 had significantly effect on general well-being and especially on spiritual factors such religious observance. Thus, $66.3 \%$ of participants increased their religious activities, even that they were exempt from holding congregational prayers every day, Friday's prayer and Eid days. This result goes in line with other research showing increasing manifestations of religions in time of natural disasters [12].

Although women are found to be more religious than men and more likely to use religious coping in another study [13], our study did not demonstrate gender differences in religious coping response to this event $(\mathrm{p}=0.180 ; \mathrm{p}=0.162)$.

Higher-educated participants used more PRC $(\mathrm{p}=0.002)$. Our findings are supported by another study [14] showing that higher-educated participants used less NRC.

Accordingly, during the COVID-19 pandemic, interest in religion has soared [15]. In fact, influenced with such stress and negative life events, people can often find comfort, hope, and practical social support from religious beliefs, practices, and communities (O'Brien et al., 2019). They look up to the Holy Qur'an and teachings of the Prophet (PBUH) (Hadiths) for guidance [16].

Research showed that religion may be a particularly powerful resource for mental health since it could be associated with decreased psychological distress. It also 
provides a source of attitudes and cognitions that can reframe negative events into less stressful frames provides a source of social support that appears to increase self-control and enhances gratitude. It includes practices and behaviors such as prayer, study, and mindfulness that are linked to lower negative affect [17].

Our results underline that Tunisian adults turn to $\mathrm{PRC}$ as a resource $(37.5 \%)$, and that $\mathrm{NRC}$ is less common (5\%). In fact, PRC strategies include seeking God's love and care, reframing difficult situations as opportunities for growth, and partnering with God in times of distress to find strength and relief. NRC reflects conflict within oneself, with God, and with other people. An individual employing negative religious coping in response to stress might doubt God's love, perceive negative life events to be a form of punishment, and feel abandoned by God and his community of faith [16].

Further, a recent American study published on July 2020 [17] demonstrated that first PRC has been associated with various favorable outcomes such as decreased depression and anxiety as well as increased psychological well-being in the general population, however, NRC involves religious beliefs and behaviors that exacerbate stress and anxiety [17].

In our sample, PRC was correlated with higher anxiety level $(p=0.044)$. Contrariwise, another study exploring the psychological distress and coping styles in the early stages of corona virus disease in the general mainland Chinese population suggests that those with negative coping style have higher levels of psychological distress [18].

In our study, some limitations need to be taken into consideration. First, it is a cross-sectional study which does not allow the investigation of changes in individuals 'coping strategy across different periods of the SARS epidemic, which could provide a fuller picture of the psychological impact of the outbreak. Besides, the number of participants is limited who may not be representative of the entire Tunisian population.

\section{Conclusion}

In conclusion, the COVID-19 outbreak in Tunisia had an impact on the mental health status of the general public even after the lockdown resolution.

Our results indicate that religious coping is a part of this pandemic's experience and it help in coping with this event. The role of religion in coping with this situation is important. Some people may use positive religious coping strategies while others tend to use more negative coping strategies.

So, it is important to recognize the potential for such life crises to shake people not only psychologically, socially, and physically, but religiously and spiritually as well.

\section{Data Availability}

The data generated during and/or analyzed during the current study are not publicly available to protect study participant privacy.

\section{Conflicts of Interest}

The authors declare that they have no competing interests.

\section{Ethics declarations}

\section{Consent of Publication}

Informed consent to participate in the study was obtained from participants.

\section{Human and Animal Rights}

This research was conducted in accordance with the ethical standards.

\section{Abbreviations}

NRC: negative religious coping, PRC: positive religious coping, R-COPE: brief religious coping scale, HADS-A: Hospital anxiety and depression scale-anxiety

\section{References}

[1] Wiersinga WJ, Rhodes A, Cheng AC, Peacock SJ, Prescott HC. Pathophysiology, Transmission, Diagnosis, and Treatment of Coronavirus Disease 2019 (COVID-19): A Review. JAMA. 2020 Aug 25; 324 (8): 782-93.

[2] Man MA, Toma C, Motoc NS, Necrelescu OL, Bondor CI, Chis AF, et al. Disease Perception and Coping with Emotional Distress During COVID-19 Pandemic: A Survey Among Medical Staff. Int J Environ Res Public Health. 2020 Jul 7; 17 (13).

[3] Dorsaf L. Coronavirus: Confinement total en Tunisie [Internet]. Tunisie Numerique. 2020 [cited 2020 Aug 31]. Available from: https://www.tunisienumerique.com/coronavirus-confinementtotal-en-tunisie/.

[4] Sim K, Chua HC. The psychological impact of SARS: a matter of heart and mind. CMAJ. 2004 Mar 2; 170 (5): 811-2.

[5] As DZ. Questionnaire H. A. D (Hospital Anxiety and Depression scale).: 1 .

[6] Pargament K, Feuille M, Burdzy D. The Brief RCOPE: Current Psychometric Status of a Short Measure of Religious Coping. Religions. 2011 Feb 22; 2 (1): 51-76.

[7] Jeong H, Yim HW, Song Y-J, Ki M, Min J-A, Cho J, et al. Mental health status of people isolated due to Middle East Respiratory Syndrome. Epidemiol Health [Internet]. 2016 Nov 5 [cited 2020 Sep 2]; 38. Available from: https://www.ncbi.nlm.nih.gov/pmc/articles/PMC5177805/.

[8] Brooks SK, Webster RK, Smith LE, Woodland L, Wessely S, Greenberg N, et al. The psychological impact of quarantine and how to reduce it: rapid review of the evidence. The Lancet. 2020 Mar; 395 (10227): 912-20.

[9] Lau ALD, Chi I, Cummins RA, Lee TMC, Chou K-L, Chung LWM. The SARS (Severe Acute Respiratory Syndrome) pandemic in Hong Kong: effects on the subjective wellbeing of elderly and younger people. Aging Ment Health. 2008 Nov; 12 (6): 746-60. 
[10] Mihashi M, Otsubo Y, Yinjuan X, Nagatomi K, Hoshiko M, Ishitake T. Predictive factors of psychological disorder development during recovery following SARS outbreak. Health Psychology. 2009 Jan; 28 (1): 91-100.

[11] Peng EY-C, Lee M-B, Tsai S-T, Yang C-C, Morisky DE, Tsai L-T, et al. Population-based Post-crisis Psychological Distress: An Example From the SARS Outbreak in Taiwan. Journal of the Formosan Medical Association. 2010 Jul; 109 (7): 524-32.

[12] Bentzen JS. In Crisis, We Pray: Religiosity and the COVID-19 Pandemic.: 57.

[13] Hvidtjørn D, Hjelmborg J, Skytthe A, Christensen K, Hvidt NC. Religiousness and Religious Coping in a Secular Society: The Gender Perspective. J Relig Health. 2014 Oct; 53 (5): 1329-41.

[14] Zwingmann C, Mller C, Krber J, Murken S. Religious commitment, religious coping and anxiety: a study in German patients with breast cancer. European Journal of Cancer Care. 2008 Jul; 17 (4): 361-70.
[15] Ano GG, Vasconcelles EB. Religious coping and psychological adjustment to stress: A meta-analysis. J Clin Psychol. 2005 Apr; 61 (4): 461-80.

[16] O'Brien B, Shrestha S, Stanley MA, Pargament KI, Cummings J, Kunik ME, et al. Positive and negative religious coping as predictors of distress among minority older adults. Int J Geriatr Psychiatry. 2019 Jan; 34 (1): 54-9.

[17] Pirutinsky S, Cherniak AD, Rosmarin DH. COVID-19, Mental Health, and Religious Coping Among American Orthodox Jews. J Relig Health. 2020 Jul 23.

[18] The psychological distress and coping styles in the early stages of the 2019 coronavirus disease (COVID-19) epidemic in the general mainland Chinese population: A web-based survey [Internet]. [cited 2021 Jul 4]. Available from: https://journals.plos.org/plosone/article?id=10.1371/journal.po ne. 0233410 . 